\title{
Identification and functional characterization of long non-coding RNAs in human gastric cancer
}

\author{
CHENG-YUN LI ${ }^{1}$, GE-YU LIANG ${ }^{1}$, WEN-ZHUO YAO ${ }^{1}$, JING SUI ${ }^{1}$, XIAN SHEN $^{1}$, YAN-QIU ZHANG ${ }^{1}$, \\ SHU-MEI MA ${ }^{1}$, YAN-CHENG YE ${ }^{2}$, ZHI-YI ZHANG ${ }^{2}$, WEN-HUA ZHANG ${ }^{2}$, LI-HONG YIN ${ }^{1}$ and YUE-PU PU ${ }^{1}$ \\ ${ }^{1}$ Key Laboratory of Environmental Medicine Engineering, Ministry of Education, School of Public Health, \\ Southeast University, Nanjing, Jiangsu 210009; ${ }^{2}$ Department of Cancer Epidemiology, Wuwei Cancer Registry, \\ Gansu Wuwei Tumor Hospital, Wuwei, Gansu 733000, P.R. China
}

Received October 20, 2015; Accepted March 17, 2017

DOI: $10.3892 / \mathrm{ol} .2018 .8369$

\begin{abstract}
Abnormal regulation of long non-coding RNAs (lncRNAs) appears to be a primary feature of numerous types of human cancer. However, the association between the dysregulation of IncRNAs and functional alterations in gastric cancer (GC) remains unclear. In previous studies, we applied microarray and bioinformatics analyses to screen for key lncRNAs from the tumor tissues and matched adjacent non-tumor tissues of 10 patients with GC. There were seven key lncRNAs demonstrated to be significantly different between carcinoma tissues and adjacent non-tumor tissues. In the present study, the expression of these seven selected IncRNAs were validated in 82 patients with GC to further investigate the association between lncRNAs and GC clinical characterization. Reverse transcription-quantitative polymerase chain reaction (RT-qPCR) results demonstrated that RP5-919F19, MCPH1 antisense RNA 1 (CTD-2541M15) and urothelial carcinoma-associated 1 (UCAl) exhibited consistent upregulation in cancer compared with adjacent non-tumor tissues, whereas AP000459, LOC101928316, tumor suppressor candidate 8 (LINC01071) and maternally expressed 3 (MEG3) showed consistent downregulation. The results from the microarray and RT-qPCR experiments achieved 100\% agreement. A correlation analysis indicated that RP5-919F19, LOC101928316 and MEG3 were significantly associated with tumor differentiation degree, RP5-919F19, UCA1 and MEG3 were significantly associated with lymph node metastasis, and RP5-919F19, CTD-2541M15 and UCA1 were significantly associated with tumor-node-metastasis stage $(\mathrm{P}<0.05)$. In addition, it was identified that the differential expression of
\end{abstract}

Correspondence to: Professor Ge-Yu Liang, Key Laboratory of Environmental Medicine Engineering, Ministry of Education, School of Public Health, Southeast University, 87 Dingjiaqiao Street, Nanjing, Jiangsu 210009, P.R. China

E-mail: lianggeyu@163.com

Key words: gastric cancer, long non-coding RNA, function, biomarker
LINC01071 and LOC101928316 significantly correlated with the age and gender of the GC patients, respectively $(\mathrm{P}<0.05)$. The results suggest that the lncRNAs RP5-919F19, LOC101928316, CTD-2541M15, UCA1 and MEG3 are closely associated with the invasion and metastasis of GC, which reveals these indicators as potential specificity biomarkers for the diagnosis, prognosis and classification of GC. Thus, these lncRNAs merit further study as novel candidate biomarkers for the clinical diagnosis of GC and as potential targets for therapy.

\section{Introduction}

Gastric cancer (GC) is one of the most lethal types of cancer and has been increasing in incidence and mortality over the last several decades. In China, it has been estimated that $\sim 464,000$ new cases were diagnosed in 2012, which accounts for over $40 \%$ of the total cases $(\sim 989,600)$ worldwide (1). According to evidence from clinical studies, the majority of patients with GC are diagnosed at an advanced stage and are thus not suitable for radical surgery (2). Previous studies have also reported that earlier diagnosis and treatment of GC could produce a 5-year survival rate of $>90 \%$ (3).

Recent developments in the field of digestive system endoscopy have been remarkable due to their association with decreased trauma, accelerated recovery and fewer complications $(4,5)$. However, endoscopic biopsy and observation of pathological morphology are unable to detect all precancerous lesions associated with early GC (6). Therefore, improvements in the early-stage diagnosis of GC and identification of sensitive and specific biomarkers for early detection are important research topics. These issues will be resolved by further investigation into the pathogenesis of GC as well as the identification of novel and reliable biomarkers for early diagnosis or molecular therapeutic targets for the treatment of this disease.

Over the past decade, various studies have indicated that the human transcriptome comprises not only of protein-coding mRNAs, but also a large number of non-protein-coding RNAs (7). Although a large number of studies focus on microRNAs (miRNAs; 18-200 nucleotides), a wide array of critical regulatory roles in biology have been associated with long non-coding RNAs (lncRNAs) (8). lncRNAs, which are 
tentatively defined as a series of RNA transcripts that are $>200$ nucleotides in length, have been confirmed as essential regulators in almost all aspects of biology (9). Accumulating evidence suggests that lncRNAs are important in tumorigenesis (10). As it is the functional end-product, the level of lncRNA expression correlates directly with the level of the active molecule (11). Thus, the use of lncRNAs in diagnostics has inherent advantages over the use of protein-coding RNAs. In addition, lncRNAs exhibit greater tissue specificity compared with protein-coding mRNAs and miRNAs, making them appealing in the search for novel diagnostic and prognostic cancer biomarkers (12). Therefore, further studies on GC tissues from endoscopic biopsy may aid in establishing the associations between lncRNAs and GC.

Previous studies have identified a subset of lncRNAs that are associated with GC, indicating their wide participation in the development and progression of GC $(13,14)$. However, the biological functions and mechanisms of these lncRNAs remain unexplored (11). In the present study, differential expression profiles of lncRNAs and mRNAs were detected in advanced GC tissues and adjacent non-tumor tissues by microarray analysis. In addition, the present study aimed to identify the associations between significant differences in lncRNA levels and the clinicopathological characteristics of GC in order to elucidate the specific functions and mechanisms of these lncRNAs during GC development.

\section{Materials and methods}

Patients and tissue sample collection. Specimens from 10 patients with advanced GC, as well as their paired adjacent non-cancerous tissue specimens, were included in the lncRNA microarray analysis, and tissues from 82 patients, including 59 males and 23 females aged between 45 and 70 years, were collected for reverse transcription-quantitative polymerase chain reaction (RT-qPCR) analysis from the Gansu Wuwei Cancer Hospital (Wuwei, China) between September 2014 and May 2015. The present study was approved by the Ethics Committee of the Gansu Wuwei Cancer Hospital. All patients provided written informed consent to participate in the present study. All patients were assigned a diagnosis of GC based on histopathology and clinical history.

In addition, clinical information was recorded for each patient, including age, gender, tumor grade, tumor location, tumor stage, degree of differentiation, tumor-node-metastasis (TNM) stage, lymph node metastasis status and date of resection. The pathologist assessed the tumor by microscopic examination in every case, and the percentage of tumor tissue was estimated to be $\geq 80 \%$. No patients had received preoperative radiotherapy or chemotherapy. Adjacent non-cancerous tissues were located $\geq 5 \mathrm{~cm}$ from the tumor edge. Tissue samples were immersed in RNAlater (Ambion; Thermo Fisher Scientific, Inc., Austin, TX, USA) and stored at $-80^{\circ} \mathrm{C}$ until use.

Isolation of RNA. Total RNA was isolated from the GC tissues and adjacent non-tumor gastric mucosal epithelium using TRIzol reagent (Invitrogen; Thermo Fisher Scientific, Inc., Carlsbad, CA, USA) according to the manufacturer's instructions. The concentration and integrity of isolated RNA was assessed using a NanoDrop 1000 spectrophotometer (NanoDrop Technologies; Thermo Fisher Scientific, Inc.,
Wilmington, DE, USA). Finally, total RNA integrity was assessed by agarose gel electrophoresis.

IncRNA microarray analysis. RNA samples were isolated from 10 patients by pooling RNA from 2,4 and 4 patients, respectively, into three groups as 'one sample'. Thus, three pairs of pooled RNA samples were generated from GC specimens and their paired adjacent non-cancerous tissues. These three pairs of RNA samples were subjected to microarray analysis using a RiboArray Custom Array 1*90K (Guangzhou RiboBio Co., Ltd., Guangzhou, China), which could detect 32,987 lncRNAs from a number of authoritative data sources, including RefSeq (National Center for Biotechnology Information) (https://www .ncbi.nlm.nih.gov/gene/?term=),H-invDB (http://h-invitational. jp/hinv/ahg-db/index.jsp), UCSC (http://genome.ucsc.edu/) LncRNAdb (http://www.lncrnadb.org/\#opennewwindow), and GENCODE LncRNA (https://www.gencodegenes.org). Signals were normalized using the median center tool for the genes. Analysis of variance (ANOVA) was used to compare differentially expressed lncRNAs and mRNAs.

In a previous study, we built an IncRNA-mRNA co-expression network that was based on the theory of competing endogenous RNAs, and the differentially expressed lncRNAs and mRNAs that were selected from GC specimens and their paired adjacent non-cancerous tissues (15). In the present study, standard selection criteria to identify differentially expressed lncRNAs and mRNAs were established at $\mathrm{P}<0.05$ and fold change $>2$. The IncRNA-mRNA networks were constructed based on the associations between the differentially expressed lncRNAs and mRNAs in the previous study (15), and visualized using Cytoscape v3.0 (National Institute of General Medical Sciences, National Institutes of Health, Rockville, MD, USA).

$R T-q P C R$ analysis. GAPDH was selected as the endogenous standard. RT reactions were conducted in two steps. First, the mixture containing $1 \mu \mathrm{g}$ of RNA samples was incubated in a 96-well plate for $10 \mathrm{~min}$ at $70^{\circ} \mathrm{C}$ and held at $4^{\circ} \mathrm{C}$. Subsequently, the 11.1- $\mu 1$ mixture, which comprised $4 \mu 1 \mathrm{MgCl}_{2}(25 \mathrm{mM})$, $2 \mu 1$ 10X RT buffer (Promega Corporation, Madison, WI, USA), $2 \mu \mathrm{l}$ dNTPs (10 mM; Promega Corporation), $0.6 \mu 1$ AMV reverse transcriptase $(15 \mathrm{U} / \mu \mathrm{l}), 0.5 \mu \mathrm{l}$ RNAsin, $2 \mu \mathrm{l}$

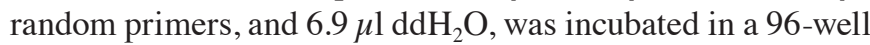
plate at $25^{\circ} \mathrm{C}$ for $10 \mathrm{~min}, 42^{\circ} \mathrm{C}$ for $15 \mathrm{~min}, 95^{\circ} \mathrm{C}$ for $5 \mathrm{~min}$, and subsequently held at $4^{\circ} \mathrm{C}$.

qPCR was performed to detect the expression levels of candidate lncRNAs with the StepOnePlus ${ }^{\mathrm{TM}}$ Real-Time PCR System (Applied Biosystems; Thermo Fisher Scientific, Inc., Waltham, MA, USA) and GoTaq ${ }^{\circledR}$ qPCR Master Mix (Promega Corporation), according to the manufacturer's protocol. The total PCR reaction volume was $10 \mu \mathrm{l}$ and included $1 \mu \mathrm{l}$ cDNA, $5 \mu \mathrm{l} \mathrm{GoTaq}^{\circledR}$ qPCR Master Mix, $0.2 \mu \mathrm{M}$ PCR primers (Shanghai Generay Biotech Co., Ltd., Shanghai, China) and RNase-free water. The reaction was performed at $95^{\circ} \mathrm{C}$ for $2 \mathrm{~min}$, followed by 40 cycles of $95^{\circ} \mathrm{C}$ for $15 \mathrm{sec}, 60^{\circ} \mathrm{C}$ for $30 \mathrm{sec}$ and $72^{\circ} \mathrm{C}$ for $30 \mathrm{sec}$. A dissociation curve was analyzed from $60-95^{\circ} \mathrm{C}$. Primers used for real-time RT-PCR as shown in Table I. RT-qPCR relative fold-change results were calculated using the $2^{-\Delta \Delta \mathrm{Cq}}$ method [where $\Delta \mathrm{Cq}=\left(\mathrm{Cq}_{\mathrm{RNAs}}-\mathrm{Cq}_{\mathrm{GAPDH}}\right)$; and $\Delta \Delta \mathrm{Cq}=\Delta \mathrm{Cq}_{\text {tumor tissues }}-\Delta \mathrm{Cq}_{\text {adjacent non-tumor tissues }}$ ] (16). All experiments were repeated three times. 
Table I. Primer sequences used in the reverse transcription-quantitative polymerase chain reaction validation of long non-coding RNAs.

\begin{tabular}{|c|c|c|c|}
\hline Gene symbol & Primer sequences, 5'-3' & Target size, bp & $\mathrm{Tm},{ }^{\circ} \mathrm{C}$ \\
\hline RP5-919F19-F & TGGAGGAAGGAGAAGGTCAT & 88 & 59 \\
\hline RP5-919F19-R & CGTGTCAGGTAGCCAAGG & & \\
\hline CTD-2541M15-F & GATACTGCCTGTGACCTG & 120 & 59 \\
\hline CTD-2541M15-R & GACTAAGCGTGACTCCTG & & \\
\hline UCA1-F & TCCACACCCAAAACAAAA & 200 & 59 \\
\hline UCA1-R & GCССТСТААСАACAAACAAC & & \\
\hline AP000459-F & CCATCTTTGAGGGCTTTT & 141 & 59 \\
\hline AP000459-R & GGTGTGTCATTTTGTTTTCC & & \\
\hline LOC 101928316-F & AACAACGGGGACATTAGG & 119 & 59 \\
\hline LOC $101928316-\mathrm{R}$ & AACTGGAAACATCACATAGCA & & \\
\hline LINC01071-F & TTTCCATAAGGCACGATT & 220 & 59 \\
\hline LINC01071-R & CСТАACCCACCACATTCA & & \\
\hline MEG3-F & TGCCCATCTACACCTCAC & 112 & 59 \\
\hline MEG3-R & TCСТСТTCATCСТTTGCC & & \\
\hline GAPDH-F & GGGAGCCAAAAGGGTCATCA & 203 & 60 \\
\hline GAPDH-R & TGATGGCATGGACTGTGGTC & & \\
\hline
\end{tabular}

Statistical analysis. SPSS software version 18.0 (SPSS, Inc., Chicago, IL, USA) was used to perform the data analysis. Results are presented as mean \pm standard error. Statistical analysis was performed using a Student's t-test for comparison of two groups in the microarray analysis, and one-way analysis of variance for multiple comparisons with the Student-Newman-Keuls post hoc test. For all comparisons, differences with $\mathrm{P}<0.05$ were considered statistically significant. In addition, a conditional logistic regression analysis was used to evaluate any association between differentially expressed IncRNAs and the characteristics of patients with GC.

\section{Results}

Screening of candidate lncRNAs by microarray and bioinformatics analysis. Previous microarray analysis identified that 1,046 lncRNAs, including 427 upregulated and 619 downregulated lncRNAs, were significantly differentially expressed (fold-change $\geq 2.0$ ) between advanced GC lesions and adjacent non-tumor tissues. The present study identified key lncRNAs, and a total of 6 key lncRNAs were revealed to be overexpressed in tumor tissues [RP5-919F19, RP11-54O7, RP11-20123, MCPH1 antisense RNA 1 (CTD-2541M15), AC010731, and urothelial carcinoma-associated 1 (UCAI); Table II], in addition, there were 8 key lncRNAs were found to be downregulated in tumor tissues [AP000459, LOC101928316, RP11-167N4, tumor suppressor candidate 8 (LINC01071), RP11-111K18, TTC28 antisense RNA 1 (TTC28-AS1), MTOR antisense RNA 1 (MTOR-AS1), and maternally expressed 3 (MEG3); Table II]. The data also revealed that there were significant differences in the expression levels of RP5-919F19, CTD-2541M15, UCA1, AP000459, LOC101928316, LINC01071 and MEG3 in tumor tissues compared with adjacent non-tumor tissues $(\mathrm{P}<0.05)$. Clustering analysis was performed for all 14 abnormally expressed key lncRNAs (Fig. 1).
Verification of selected IncRNA expression in GC tissues. RT-qPCR was performed to confirm the reliability and validity of the detected expression levels of the selected lncRNAs in $82 \mathrm{GC}$ tissues and adjacent non-tumor tissues. The results demonstrated that RP5-919F19, CTD-2541M15 and UCA1 showed consistent upregulation compared with adjacent non-tumor tissues, while AP000459, LOC101928316, LINC01071 and MEG3 showed consistent downregulation (Table III). A histogram (Fig. 2) shows the fold-changes detected by RT-qPCR $\left(2^{-\Delta \Delta C q}\right)$ and lncRNA microarray data. The consistency between the microarray and RT-qPCR data confirms the reliability of the results.

Association between the identified IncRNAs and clinicopathological characteristics of $G C$. The associations between the expression levels of the seven selected lncRNAs in GC samples and the clinicopathological characteristics of the patients were analyzed. The results identified that one lncRNA, AP000459, had no statistically significant associations with the following clinicopathological characteristics: Patient gender or age; tumor size or differentiation degree; TNM stage; or lymph node metastasis status. However, the remaining six lncRNAs each demonstrated significant associations with certain characteristics: RP5-919F19, LOC101928316 and MEG3 were significantly associated with tumor differentiation degree; RP5-919F19, UCA1 and $M E G 3$ were significantly associated with lymph node metastasis status; and RP5-919F19, CTD-2541M15 and UCA1 were significantly associated with TNM stage (all $\mathrm{P}<0.05$ ). In addition, LINC01071 expression was associated with patient age; UCA1 was associated with tumor size; and LOC101928316 was associated with the sex of the patient (all $\mathrm{P}<0.05$; Tables IV-X).

Association between candidate IncRNAs and the lymph node metastasis of GC. Conditional logistic regression analysis 
Table II. Differential expression of key lncRNAs in gastric cancer.

\begin{tabular}{|c|c|c|c|}
\hline Name (lncRNA) & Transcript-ID & Regulation & Fold-change \\
\hline$R P 5-919 F 19^{a}$ & URS0000515CAC & Up & 36.92 \\
\hline$R P 11-54 O 7$ & URS00005B803E & Up & 32.52 \\
\hline$R P 11-20 I 23$ & URS00002B7786 & Up & 32.43 \\
\hline$C T D-2541 M 15^{\mathrm{a}}$ & URS0000359EF8 & Up & 28.03 \\
\hline AC010731 & ENST00000543490 & Up & 25.33 \\
\hline$U C A 1^{\mathrm{a}}$ & NR_015379 & Up & 11.51 \\
\hline$A P 000459^{\mathrm{a}}$ & URS000048CBED & Down & -23.26 \\
\hline$L O C 101928316^{\mathrm{a}}$ & XR_428890 & Down & -22.73 \\
\hline$R P 11-167 N 4$ & ENST00000537019 & Down & -22.73 \\
\hline$R P 11-111 K 18$ & URS00002FCA1A & Down & -18.52 \\
\hline$L I N C 01071^{\mathrm{a}}$ & NR_104174 & Down & -18.52 \\
\hline TTC28-AS1 & ENST00000430525 & Down & -17.88 \\
\hline MTOR-AS1 & NR_046600 & Down & -16.67 \\
\hline$M E G 3^{\mathrm{a}}$ & NR_046473 & Down & -2.19 \\
\hline
\end{tabular}

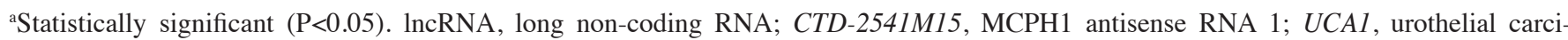
noma-associated 1; LINC01071, tumor suppressor candidate 8; TTC28-AS1, TTC28 antisense RNA 1; MTOR-AS1, MTOR antisense RNA 1; $M E G 3$, maternally expressed 3.

Table III. Relative expression levels of lncRNAs in 82 pairs of GC and non-tumor tissues.

\begin{tabular}{|c|c|c|c|c|c|}
\hline \multirow[b]{2}{*}{ Gene symbol } & \multicolumn{2}{|c|}{$\begin{array}{l}\text { lncRNA expression, } \Delta \mathrm{Cq} \\
\text { (mean } \pm \text { standard deviation) }\end{array}$} & \multirow[b]{2}{*}{$2^{-\Delta \Delta C q}$} & \multirow[b]{2}{*}{ Change in expression in GC } & \multirow[b]{2}{*}{ P-value } \\
\hline & GC tissues & Adjacent non-tumor tissues & & & \\
\hline RP5-919F19 & $11.448 \pm 4.136$ & $12.393 \pm 3.613$ & 3.778 & Up & $0.000^{\mathrm{a}}$ \\
\hline$C T D-2541 M 15$ & $8.041 \pm 2.734$ & $8.729 \pm 2.633$ & 6.459 & Up & $0.001^{\mathrm{a}}$ \\
\hline UCA1 & $9.666 \pm 3.459$ & $10.764 \pm 4.011$ & 8.521 & Up & $0.000^{\mathrm{a}}$ \\
\hline AP000459 & $12.234 \pm 5.216$ & $10.460 \pm 4.938$ & -13.073 & Down & $0.000^{\mathrm{a}}$ \\
\hline LOC101928316 & $10.198 \pm 3.749$ & $8.789 \pm 3.677$ & -10.878 & Down & $0.000^{\mathrm{a}}$ \\
\hline LINC01071 & $13.757 \pm 4.260$ & $12.152 \pm 4.809$ & -13.062 & Down & $0.000^{\mathrm{a}}$ \\
\hline MEG3 & $8.079 \pm 4.892$ & $7.159 \pm 4.479$ & -6.322 & Down & $0.003^{\mathrm{a}}$ \\
\hline
\end{tabular}

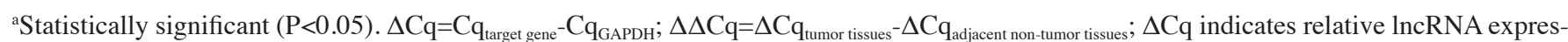
sion level (the higher the $\triangle \mathrm{Cq}$ value, the lower the lncRNA expression). lncRNA, long non-coding RNA; GC, gastric cancer; CTD-2541M15, MCPH1 antisense RNA 1; UCA1, urothelial carcinoma-associated 1; LINC01071, tumor suppressor candidate 8; MEG3, maternally expressed 3.

was used to evaluate the association between differentially expressed lncRNAs and the lymph node metastasis status of GC. As shown in Table XI, a significantly increased risk of lymph node metastasis was associated with the increased expression of RP5-919F19 [odds ratio (OR), 1.199] and reduced expression of $M E G 3$ (OR, 0.924). This suggested that RP5-919F19 and MEG3 may participate in the lymphatic metastasis of GC.

\section{Discussion}

Although there appears to have been a steady global decline in the incidence of GC and associated mortality over several decades (17), it is still a disease of substantial incidence and mortality in China, with a large number of patients diagnosed at an advanced stage and with a poor prognosis (18). Furthermore, endoscopic biopsy and pathological morphological observation cannot detect all precancerous lesions and early stages of GC (19). Therefore, in order to improve this situation, the identification of the genes and regulatory mechanisms involved in lymph node metastasis has become a research area of increasing interest. In recent years, a large number of lncRNAs have been identified in genetic studies, and have been found to be associated with various diseases (20). The mechanisms by which lncRNAs may participate in cancer development are currently being studied (21-23). However, IncRNAs in GC have predominantly been reported in Western countries and in Japan, whereas few studies have been 
Table IV. Association between the expression of RP5-919F19 and clinicopathological characteristics of gastric cancer patients.

\begin{tabular}{|c|c|c|c|}
\hline Variable & Cases, n (\%) & $\begin{array}{l}\text { Expression of } R P 5-919 F 192^{-\triangle \Delta C q} \\
\quad \text { (mean } \pm \text { standard deviation) }\end{array}$ & P-value \\
\hline Gender & & & 0.672 \\
\hline Male & $59(72)$ & $4.284 \pm 11.597$ & \\
\hline Female & $23(28)$ & $3.059 \pm 9.363$ & \\
\hline Age, years & & & 0.405 \\
\hline$\leq 50$ & $30(37)$ & $2.446 \pm 12.746$ & \\
\hline$>50$ & $52(63)$ & $4.617 \pm 9.843$ & \\
\hline Tumor size, $\mathrm{cm}$ & & & 0.238 \\
\hline$\leq 5$ & $43(52)$ & $2.434 \pm 11.066$ & \\
\hline$>5$ & $39(48)$ & $5.404 \pm 10.823$ & \\
\hline Degree of differentiation & & & $0.006^{\mathrm{a}}$ \\
\hline Well/moderately & $28(34)$ & $-0.638 \pm 6.568$ & \\
\hline Poorly & $54(66)$ & $6.452 \pm 12.135$ & \\
\hline TNM stage & & & $0.015^{\mathrm{a}}$ \\
\hline $\mathrm{I} / \mathrm{II}$ & $44(54)$ & $1.170 \pm 7.709$ & \\
\hline III/IV & $38(46)$ & $7.264 \pm 13.440$ & \\
\hline Lymph node status & & & $0.029^{\mathrm{a}}$ \\
\hline No metastasis & $36(44)$ & $0.890 \pm 7.236$ & \\
\hline Metastasis & $46(56)$ & $6.337 \pm 12.893$ & \\
\hline
\end{tabular}

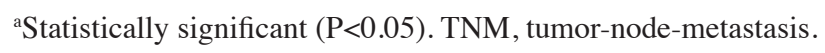

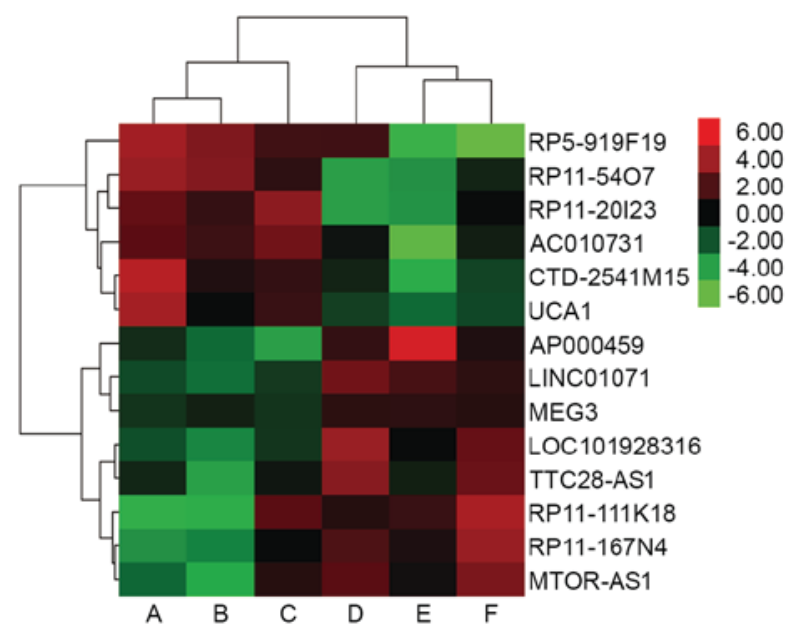

Figure 1. Clustering analysis diagram of the microarray results. Red indicates upregulated lncRNA expression and green indicates downregulated lncRNA expression. A-C are the groups of gastric cancer tissues, and D-F are the groups of adjacent non-tumor tissues. IncRNA, long non-coding RNA; CTD-2541M15, MCPH1 antisense RNA 1; UCA1, urothelial carcinoma-associated 1, LINC01071, tumor suppressor candidate 8; MEG3, maternally expressed 3; TTC28-AS1, TTC28 antisense RNA 1; MTOR-AS1, MTOR antisense RNA 1.

performed on Chinese populations (24). Although the mechanism of GC has been widely studied, the exact pathogenesis of this disease remains unclear (25). The molecular pathology of GC also varies among populations, mainly due to differential exposures to disease risk factors, including customs and habits, Helicobacter pylori variants, and medical conditions (26). In

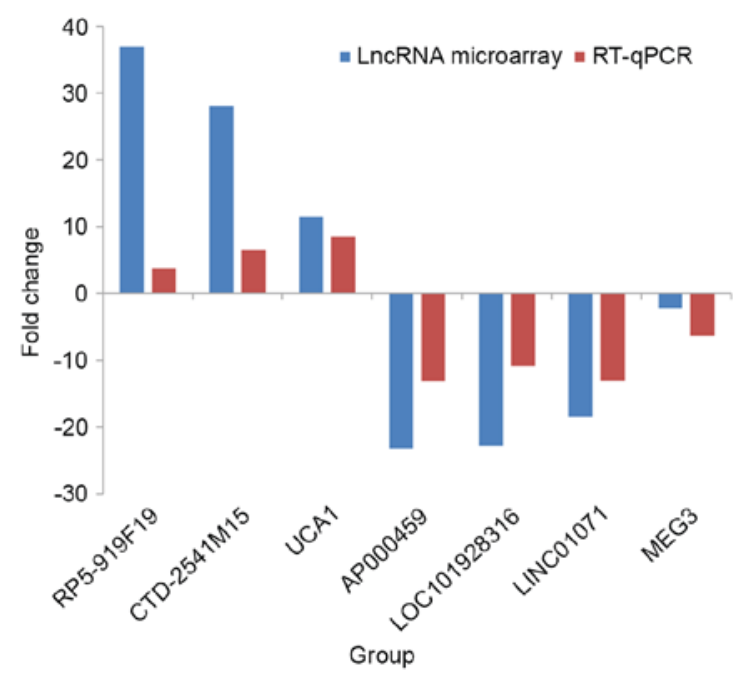

Figure 2. RT-qPCR validation of seven differentially expressed lncRNAs. Comparison of fold-change $\left(2^{-\Delta \Delta C q}\right)$ of $1 n c R N A s$ between tumor and adjacent non-tumor tissues, identified by microarray analysis and RT-qPCR results. lncRNA, long non-coding RNA; RT-qPCR, reverse transcription-quantitative polymerase chain reaction; CTD-2541M15, MCPH1 antisense RNA 1; UCA1, urothelial carcinoma-associated 1; LINC01071, tumor suppressor candidate $8 ; M E G 3$, maternally expressed 3 .

the present study, the aim was to establish lncRNA expression profiles for $\mathrm{GC}$ in a known high-risk population in Wuwei, north-west China, and to investigate the association between significant differential expression of various lncRNAs and the clinicopathological characteristics of GC. 
Table V. Association between the expression of CTD-2541M15 and clinicopathological characteristics of gastric cancer patients.

\begin{tabular}{|c|c|c|c|}
\hline Variable & Cases, n (\%) & $\begin{array}{c}\text { Expression of } C T D-2541 M 15 \\
2^{-\Delta \Delta \mathrm{Cq}}(\text { mean } \pm \text { standard deviation })\end{array}$ & P-value \\
\hline Gender & & & 0.376 \\
\hline Male & $59(72)$ & $2.643 \pm 7.687$ & \\
\hline Female & $23(28)$ & $1.108 \pm 3.997$ & \\
\hline Age, years & & & 0.176 \\
\hline$\leq 50$ & $30(37)$ & $0.618 \pm 6.310$ & \\
\hline$>50$ & $52(63)$ & $2.858 \pm 7.537$ & \\
\hline Tumor size, $\mathrm{cm}$ & & & 0.449 \\
\hline$\leq 5$ & $43(52)$ & $1.724 \pm 7.374$ & \\
\hline$>5$ & $39(48)$ & $2.902 \pm 6.368$ & \\
\hline Degree of differentiation & & & 0.488 \\
\hline Well/moderately & $28(34)$ & $1.487 \pm 6.306$ & \\
\hline Poorly & $54(66)$ & $2.615 \pm 7.201$ & \\
\hline TNM stage & & & $0.023^{\mathrm{a}}$ \\
\hline $\mathrm{I} / \mathrm{II}$ & $44(54)$ & $0.704 \pm 4.116$ & \\
\hline III/IV & $38(46)$ & $4.214 \pm 8.920$ & \\
\hline Lymph node status & & & 0.111 \\
\hline No metastasis & $36(44)$ & $0.922 \pm 3.961$ & \\
\hline Metastasis & $46(56)$ & $3.398 \pm 8.473$ & \\
\hline
\end{tabular}

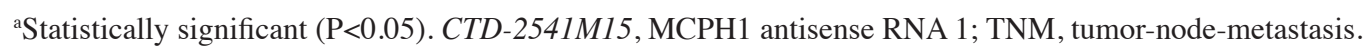

Table VI. Association between the expression of UCAI and clinicopathological characteristics of gastric cancer.

\begin{tabular}{|c|c|c|c|}
\hline Variable & Cases, n (\%) & $\begin{array}{c}\text { Expression of } U C A I \\
2^{-\Delta \Delta \mathrm{Cq}}(\text { mean } \pm \text { standard deviation })\end{array}$ & P-value \\
\hline Gender & & & 0.080 \\
\hline Male & $59(72)$ & $2.968 \pm 6.813$ & \\
\hline Female & $23(28)$ & $-0.064 \pm 4.803$ & \\
\hline Age, years & & & 0.143 \\
\hline$\leq 50$ & $30(37)$ & $3.040 \pm 10.778$ & \\
\hline$>50$ & $52(63)$ & $6.848 \pm 19.462$ & \\
\hline Tumor size, $\mathrm{cm}$ & & & $0.020^{\mathrm{a}}$ \\
\hline$\leq 5$ & $43(52)$ & $1.712 \pm 4.265$ & \\
\hline$>5$ & $39(48)$ & $13.028 \pm 29.713$ & \\
\hline Degree of differentiation & & & 0.531 \\
\hline Well/moderately & $28(34)$ & $2.968 \pm 3.459$ & \\
\hline Poorly & $54(66)$ & $4.880 \pm 14.617$ & \\
\hline TNM stage & & & $0.028^{\mathrm{a}}$ \\
\hline $\mathrm{I} / \mathrm{II}$ & $44(54)$ & $2.135 \pm 7.055$ & \\
\hline III/IV & $38(46)$ & $12.856 \pm 29.643$ & \\
\hline Lymph node status & & & $0.031^{\mathrm{a}}$ \\
\hline No metastasis & $36(44)$ & $1.258 \pm 4.306$ & \\
\hline Metastasis & $46(56)$ & $11.779 \pm 27.650$ & \\
\hline
\end{tabular}

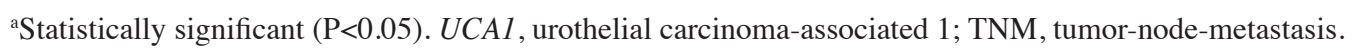

To the best of our knowledge, the present study is the first report on differential lncRNA expression in a population of patients with GC from Wuwei. The results revealed that certain lncRNA expression levels in GC samples differed 
Table VII. Association between the expression of AP000459 and clinicopathological characteristics of gastric cancer patients.

\begin{tabular}{|c|c|c|c|}
\hline Variable & Cases, n (\%) & $\begin{array}{c}\text { Expression of } A P 000459 \\
2^{-\Delta \Delta \mathrm{Cq}}(\text { mean } \pm \text { standard deviation })\end{array}$ & P-value \\
\hline Gender & & & 0.556 \\
\hline Male & $59(72)$ & $-14.210 \pm 28.921$ & \\
\hline Female & $23(28)$ & $-9.352 \pm 36.174$ & \\
\hline Age, years & & & 0.497 \\
\hline$\leq 50$ & $30(37)$ & $-10.731 \pm 27.139$ & \\
\hline$>50$ & $52(63)$ & $-6.491 \pm 22.496$ & \\
\hline Tumor size, $\mathrm{cm}$ & & & 0.531 \\
\hline$\leq 5$ & $43(52)$ & $-15.297 \pm 30.456$ & \\
\hline$>5$ & $39(48)$ & $-10.649 \pm 31.745$ & \\
\hline Degree of differentiation & & & 0.861 \\
\hline Well/moderately & $28(34)$ & $-11.958 \pm 27.352$ & \\
\hline Poorly & $54(66)$ & $-13.322 \pm 33.011$ & \\
\hline TNM stage & & & 0.924 \\
\hline $\mathrm{I} / \mathrm{II}$ & $44(54)$ & $-13.403 \pm 27.846$ & \\
\hline III/IV & $38(46)$ & $-12.689 \pm 36.611$ & \\
\hline Lymph node status & & & 0.662 \\
\hline No metastasis & $36(44)$ & $-14.864 \pm 30.097$ & \\
\hline Metastasis & $46(56)$ & $-11.601 \pm 31.939$ & \\
\hline
\end{tabular}

TNM, tumor-node-metastasis.

Table VIII. Association between the expression of LOC101928316 and clinicopathological characteristics of gastric cancer patients.

\begin{tabular}{|c|c|c|c|}
\hline Variable & Cases, n (\%) & $\begin{array}{c}\text { Expression of LOC101928316 } \\
2^{-\Delta \Delta \mathrm{Cq}}(\text { mean } \pm \text { standard deviation })\end{array}$ & P-value \\
\hline Gender & & & $0.030^{\mathrm{a}}$ \\
\hline Male & $59(72)$ & $-5.877 \pm 18.569$ & \\
\hline Female & $23(28)$ & $-23.165 \pm 28.777$ & \\
\hline Age, years & & & 0.464 \\
\hline$\leq 50$ & $30(37)$ & $-8.078 \pm 20.457$ & \\
\hline$>50$ & $52(63)$ & $-5.235 \pm 13.043$ & \\
\hline Tumor size, $\mathrm{cm}$ & & & 0.684 \\
\hline$\leq 5$ & $43(52)$ & $-4.714 \pm 12.656$ & \\
\hline$>5$ & $39(48)$ & $-6.018 \pm 14.965$ & \\
\hline Degree of differentiation & & & $0.048^{\mathrm{a}}$ \\
\hline Well/moderately & $28(34)$ & $-0.853 \pm 7.533$ & \\
\hline Poorly & $54(66)$ & $-8.436 \pm 20.044$ & \\
\hline TNM stage & & & 0.913 \\
\hline $\mathrm{I} / \mathrm{II}$ & $44(54)$ & $-5.443 \pm 14.873$ & \\
\hline III/IV & $38(46)$ & $-5.091 \pm 12.109$ & \\
\hline Lymph node status & & & 0.796 \\
\hline No metastasis & $36(44)$ & $-7.206 \pm 21.983$ & \\
\hline Metastasis & $46(56)$ & $-6.129 \pm 13.627$ & \\
\hline
\end{tabular}

aStatistically significant $(\mathrm{P}<0.05)$. TNM, tumor-node-metastasis.

from those in adjacent non-tumor tissues. Prior to this research, we had detected mRNA expression profiles with a lncRNA-mRNA combined microarray (15). Through constructing the IncRNA-mRNA co-expression network 
Table IX. Association between the expression of LINC01071 and clinicopathological characteristics of gastric cancer patients.

\begin{tabular}{|c|c|c|c|}
\hline Variable & Cases, n (\%) & $\begin{array}{c}\text { Expression of LINC01071 } \\
2^{-\Delta \Delta \mathrm{Cq}}(\text { mean } \pm \text { standard deviation })\end{array}$ & P-value \\
\hline Gender & & & 0.988 \\
\hline Male & $59(72)$ & $-12.848 \pm 37.204$ & \\
\hline Female & $23(28)$ & $-12.984 \pm 28.666$ & \\
\hline Age, years & & & $0.039^{\mathrm{a}}$ \\
\hline$\leq 50$ & $30(37)$ & $-12.208 \pm 21.206$ & \\
\hline$>50$ & $52(63)$ & $-3.312 \pm 13.601$ & \\
\hline Tumor size, $\mathrm{cm}$ & & & 0.679 \\
\hline$\leq 5$ & $43(52)$ & $-9.411 \pm 19.770$ & \\
\hline$>5$ & $39(48)$ & $-7.330 \pm 21.682$ & \\
\hline Degree of differentiation & & & 0.613 \\
\hline Well/moderately & $28(34)$ & $-11.744 \pm 22.416$ & \\
\hline Poorly & $54(66)$ & $-8.719 \pm 25.297$ & \\
\hline TNM stage & & & 0.557 \\
\hline $\mathrm{I} / \mathrm{II}$ & $44(54)$ & $-9.716 \pm 19.924$ & \\
\hline III/IV & $38(46)$ & $-6.733 \pm 21.545$ & \\
\hline Lymph node status & & & 0.908 \\
\hline No metastasis & $36(44)$ & $-9.720 \pm 20.630$ & \\
\hline Metastasis & $46(56)$ & $-10.392 \pm 27.488$ & \\
\hline
\end{tabular}

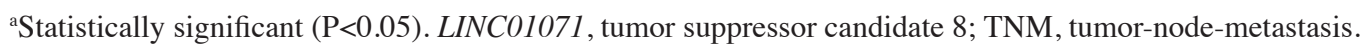

and with bioinformatics analysis, 14 key lncRNAs were identified, of which the majority were reported for the first time. Our previous research results also revealed that there were significant differences in the levels of RP5-919F19, CTD-2541M15, UCA1, AP000459, LOC101928316, LINC01071 and MEG3 in tumor tissues compared with adjacent non-tumor tissues $(\mathrm{P}<0.05)$. In the present study, these seven IncRNAs were selected for further validation by RT-qPCR in 82 pairs of human primary GC tissues and their adjacent non-tumor tissues. Subsequently, the associations between the expression levels of the seven selected lncRNAs in the GC samples and various clinicopathological characteristics were analyzed. Finally, logistic regression analysis was used to evaluate the association between differentially expressed lncRNAs and the lymph node metastasis status of GC.

In the present study, the results from the microarray and RT-qPCR experiments were in $100 \%$ agreement. Correlation analyses of the expression levels of the seven differentially expressed lncRNAs and the associated clinicopathological characteristics were performed. The results identified that six lncRNAs (RP5-919F19, CTD-2541M15, UCA1, LOC101928316, LINC01071 and MEG3) were associated with some of the following clinicopathological parameters: Patient gender, patient age, tumor size, tumor differentiation degree, TNM stage and lymph node metastasis status. Statistics revealed that RP5-919F19, LOC101928316 and $M E G 3$ were associated with tumor differentiation degree, and RP5-919F19, UCAI and MEG3 were significantly associated with lymph node metastasis $(\mathrm{P}<0.05)$, indicating that these
IncRNAs are possibly involved in the invasion and metastasis of GC. In addition, logistic regression analysis suggested that RP5-919F19 and MEG3 may participate in the lymphatic metastasis of GC. Thus, the present findings may provide a novel method of exploration that will improve the prediction of lymphatic metastatic status in patients with GC post-surgery. Notably, the abnormal expression levels of LINC01071 and LOC101928316 were significantly associated with the age and gender of the patients, respectively $(\mathrm{P}<0.05)$.

An increasing number of studies have also identified a biological link between aberrant expression of lncRNAs and GC (27). Differential expression of certain lncRNAs, including H19, UCA1, HOTAIR, PVTI, CCAT1 and MEG3, have been hypothesized to be important features of GC (28). In combining the results of our studies, only UCA1 and $M E G 3$ have been reported previously, and there was limited information available regarding the other lncRNAs.

The LncRNAdb and LncRNA Diseases databases indicated that $U C A 1$, which is located on chromosome 19, comprises three exons. UCAI was initially found and established in bladder transitional cell carcinoma (29). A recent study also reported that its expression was markedly increased in GC tissues and cell lines compared with that in the normal control tissues, and that high $U C A l$ expression correlated with poorer differentiation, tumor size, invasion depth and TNM stage in GC; furthermore, increased UCAl expression was associated with decreased overall and disease-free survival times of the patients (30).

The present study identified downregulated levels of MEG3 (which is located on the chromosome 14q32, and acts 
Table X. Association between the expression of MEG3 and clinicopathological characteristics of gastric cancer patients.

\begin{tabular}{|c|c|c|c|}
\hline Variable & Cases, n (\%) & $\begin{array}{c}\text { Expression of } M E G 3 \\
2^{-\Delta \Delta \mathrm{Cq}}(\text { mean } \pm \text { standard deviation })\end{array}$ & $\mathrm{P}$-value \\
\hline Gender & & & 0.674 \\
\hline Male & $59(72)$ & $-4.960 \pm 15.210$ & \\
\hline Female & $23(28)$ & $-3.492 \pm 7.248$ & \\
\hline Age, years & & & 0.841 \\
\hline$\leq 50$ & $30(37)$ & $-5.008 \pm 11.633$ & \\
\hline$>50$ & $52(63)$ & $-4.342 \pm 14.338$ & \\
\hline Tumor size, $\mathrm{cm}$ & & & 0.791 \\
\hline$\leq 5$ & $43(52)$ & $-4.067 \pm 13.301$ & \\
\hline$>5$ & $39(48)$ & $-4.911 \pm 13.640$ & \\
\hline Degree of differentiation & & & $0.036^{\mathrm{a}}$ \\
\hline Well/moderately & $28(34)$ & $-1.220 \pm 12.479$ & \\
\hline Poorly & $54(66)$ & $-8.317 \pm 13.822$ & \\
\hline TNM stage & & & 0.778 \\
\hline $\mathrm{I} / \mathrm{II}$ & $44(54)$ & $-4.064 \pm 13.291$ & \\
\hline III/IV & $38(46)$ & $-4.968 \pm 13.672$ & \\
\hline Lymph node status & & & $0.024^{\mathrm{a}}$ \\
\hline No metastasis & $36(44)$ & $0.822 \pm 11.519$ & \\
\hline Metastasis & $46(56)$ & $-6.447 \pm 14.730$ & \\
\hline
\end{tabular}

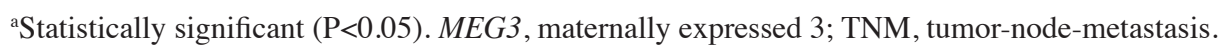

Table XI. Associations between aberrant expression of long non-coding RNAs and lymph node metastasis status of gastric cancer by logistic regression analysis.

\begin{tabular}{lcccccc}
\hline Gene symbol & $\beta$ & Standard error & Wald & P-value & Odds ratio & 95\% confidence interval \\
\hline RP5-919F19 & 0.181 & 0.070 & 6.639 & $0.010^{\mathrm{a}}$ & 1.199 & $1.044-1.376$ \\
UCA1 & 0.071 & 0.045 & 2.476 & 0.116 & 1.073 & $0.983-1.172$ \\
MEG3 & -0.079 & 0.033 & 5.689 & $0.017^{\mathrm{a}}$ & 0.924 & $0.866-0.986$ \\
\hline
\end{tabular}

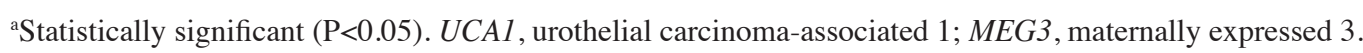

as a tumor suppressor gene) in GC tissues compared with healthy tissues; MEG3 downregulation is associated with poor prognosis and promotes cell proliferation in GC (31). These results indicate that $U C A 1$ and $M E G 3 \operatorname{lncRNAs}$ are important factors in the development of GC, as well as in the invasion and lymphatic metastasis of this cancer type.

The present study found that RP5-919F19, LOC101928316 and MEG3 were significantly associated with the degree of tumor differentiation; RP5-919F19, UCA1 and MEG3 were significantly associated with lymph node metastasis status; and RP5-919F19, CTD-2541M15 and UCA1 were significantly associated with TNM stage of GC patients These lncRNAs may prove useful for further study as novel candidate biomarkers in the diagnosis and classification of GC.

The current results indicate that RP5-919F19, CTD-2541M15, UCA1, LOC101928316 and MEG3 are potential novel molecular biomarkers that may be involved in the infiltration and metastasis of GC. In addition, according to epidemiological reports, the incidence of GC significantly increases with age, with a peak age of 50-65 years (32), and men are 2-3-fold more likely to develop GC compared with females (33). Thus, the significant associations identified between the differential expression of LINC01071 and LOC101928316 in GC tissues and patient age and gender may be of importance for diagnosis.

In conclusion, the present study revealed that $R P 5-919 F 19$, CTD-2541M15, UCA1, LOC101928316, LINC01071 and $M E G 3$ are involved in the development of GC. This provides preliminary data that may aid in increasing the understanding of the potential functions of these lncRNAs. The results also suggest that RP5-919F19, LOC101928316, CTD-2541M15, $U C A 1$ and $M E G 3$ are closely associated with the invasion and metastasis of GC, which suggests that these lncRNAs may have potential as biomarkers for the diagnosis, prognosis 
and classification of GC. Further studies of these targets are required to assess their potential clinical uses.

\section{Acknowledgements}

Not applicable.

\section{Funding}

The present study was financially supported by the National Natural Science Foundation of China (grant nos. 81673132, 81472939 and 8117261), the Qing Lan Project (grant no. 2012), the 333 Project of Jiangsu Province (grant no. 2012), the Liu Da Ren Cai Gao Feng Project of Jiangsu Province (grant no. 2013-WSW-053) and the Fundamental Research Funds for the Central Universities.

\section{Availability of data and materials}

All data generated or analyzed during this study are included in this published article.

\section{Authors' contributions}

CYL and GYL conceived and designed the study. CYL, WZY, JS and SY performed the experiments. YQZ and SMM analyzed and interpreted the results. YCY, ZYZ and WHZ performed the gastric cancer patients' tissue sample collection and quality control. LHY and YPP assisted with study design and provided advice throughout. CYL performed analysis and quality control, and was a major contributor in writing the manuscript. All authors read and approved the final manuscript.

\section{Ethics approval and consent to participate}

The present study was approved by the Ethics Committee of the Gansu Wuwei Tumor Hospital. All patients provided written informed consent to participate in the present study.

\section{Consent for publication}

All participants confirmed that the data can be published.

\section{Competing interests}

The authors declare that they have no competing interests.

\section{References}

1. Lan H, Zhu N, Lan Y, Jin K and Teng L: Laparoscopic gastrectomy for gastric cancer in China: An overview. Hepatogastroenterology 62: 234-239, 2015.

2. Yajima H, Omura N, Takahashi N, Yoshida K and Yanaga K: Additional gastrectomy after endoscopic mucosal resection for early gastric cancer. Int Surg 100: 169-172, 2015.

3. Maruyama K and Katai H: Surgical treatment of gastric cancer in Japan, trend from standardization to individualization. Chirurgia (Bucur) 109: 722-730, 2014.

4. Kwon KA: Is the double channel gastroscope useful in endoscopic mucosal resection for large sessile colon polyps? Clin Endosc 48: 89-90, 2015.
5. Qian Y, Huang J, Zhang Y, Ma LM and Fan ZN: Using a gastroscope to accomplish ERCP: A forward-viewing endoscope for cannulation of the intradiverticular papilla. Endoscopy 46 (Suppl 1) UCTN: E139, 2014.

6. Ju H, Ma Y, Liang K, Zhang C and Tian Z: Function of high-resolution manometry in the analysis of peroral endoscopic myotomy for achalasia. Surg Endosc 30: 1094-1099, 2016.

7. Yang F, Zhang L, Huo XS, Yuan JH, Xu D, Yuan SX, Zhu N Zhou WP, Yang GS, Wang YZ, et al: Long noncoding RNA high expression in hepatocellular carcinoma facilitates tumor growth through enhancer of zeste homolog 2 in humans. Hepatology 54: 1679-1689, 2011.

8. Ponting CP, Oliver PL and Reik W: Evolution and functions of long noncoding RNAs. Cell 136: 629-641, 2009.

9. Zhu YP, Bian XJ, Ye DW, Yao XD, Zhang SL, Dai B, Zhang HL and Shen YJ: Long noncoding RNA expression signatures of bladder cancer revealed by microarray. Oncol Lett 7: 1197-1202, 2014.

10. Cheng WS, Tao H,Hu EP, Liu S, Cai HR, Tao XL, Zhang L, Mao JJ and Yan DL: Both genes and lncRNAs can be used as biomarkers of prostate cancer by using high throughput sequencing data. Eur Rev Med Pharmacol Sci 18: 3504-3510, 2014.

11. Wang S and Tran EJ: Unexpected functions of lncRNAs in gene regulation. Commun Integr Biol 6: e27610, 2013.

12. Hung T and Chang HY: Long noncoding RNA in genome regulation: Prospects and mechanisms. RNA Biol 7: 582-585, 2010.

13. Lin XC, Zhu Y, Chen WB, Lin LW, Chen DH, Huang JR, Pan K, Lin Y, Wu BT, Dai Y and Tu ZG: Integrated analysis of long non-coding RNAs and mRNA expression profiles reveals the potential role of lncRNAs in gastric cancer pathogenesis. Int J Oncol 45: 619-628, 2014.

14. Gu Y, Chen T, Li G, Yu X, Lu Y, Wang H and Teng L: LncRNAs: Emerging biomarkers in gastric cancer. Future Oncol 11: 2427-2441, 2015.

15. Li C, Liang G, Yao W, Sui J, Shen X, Zhang Y, Ma S, Ye Y, Zhang Z, Zhang W, et al: Differential expression profiles of long non-coding RNAs reveal potential biomarkers for identification of human gastric cancer. Oncol Rep 35: 1529-1540, 2016.

16. Livak KJ and Schmittgen TD: Analysis of relative gene expression data using real-time quantitative PCR and the 2(-Delta Delta C(T)) method. Methods 25: 402-408, 2001.

17. Patru CL, Surlin V, Georgescu I and Patru E: Current issues in gastric cancer epidemiology. Rev Med Chir Soc Med Nat Iasi 117: 199-204, 2013.

18. Li G, Hu Y and Liu H: Current status of randomized controlled trials for laparoscopic gastric surgery for gastric cancer in China. Asian J Endosc Surg 8: 263-267, 2015.

19. RajanE,GostoutCJ,Aimore BE,MoranEA,LockeRG,SzarkaLA, Talley NJ, Deters JL, Miller CA, Knipschield MA, et al: Endoscopic full-thickness biopsy of the gastric wall with defect closure by using an endoscopic suturing device: Survival porcine study. Gastrointest Endosc 76: 1014-1019, 2012.

20. Chen G, Wang Z, Wang D, Qiu C, Liu M, Chen X, Zhang Q, Yan G and Cui Q: LncRNADisease: A database for long-non-coding RNA-associated diseases. Nucleic Acids Res 41(Database issue): D983-D986, 2013.

21. Gupta RA, Shah N, Wang KC, Kim J, Horlings HM, Wong DJ, Tsai MC, Hung T, Argani P, Rinn JL, et al: Long non-coding RNA HOTAIR reprograms chromatin state to promote cancer metastasis. Nature 464: 1071-1076, 2010.

22. Kogo R, Shimamura T, Mimori K, Kawahara K, Imoto S, Sudo T, Tanaka F, Shibata K, Suzuki A, Komune S, et al: Long noncoding RNA HOTAIR regulates polycomb-dependent chromatin modification and is associated with poor prognosis in colorectal cancers. Cancer Res 71: 6320-6326, 2011.

23. Tsai MC, Spitale RC and Chang HY: Long intergenic noncoding RNAs: New links in cancer progression. Cancer Res 71: 3-7, 2011.

24. Wang YY, Ye ZY, Zhao ZS, Tao HQ and Li SG: Systems biology approach to identification of biomarkers for metastatic progression in gastric cancer. J Cancer Res Clin Oncol 136: 135-141, 2010.

25. Zhao Z, Song Y, Piao D, Liu T and Zhao L: Identification of genes and long non-coding RNAs associated with the pathogenesis of gastric cancer. Oncol Rep 34: 1301-1310, 2015.

26. Pizzi M, Saraggi D, Fassan M, Megraud F, Di Mario F and Rugge M: Secondary prevention of epidemic gastric cancer in the model of Helicobacter pylori-associated gastritis. Dig Dis 32: 265-274, 2014. 
27. Chen X, Sun J, Song Y, Gao P, Zhao J, Huang X, Liu B, Xu H and Wang Z: The novel long noncoding RNA AC138128.1 may be a predictive biomarker in gastric cancer. Med Oncol 31: 262, 2014.

28. Li PF, Chen SC, Xia T, Jiang XM, Shao YF, Xiao BX and Guo JM: Non-coding RNAs and gastric cancer. World J Gastroenterol 20: 5411-5419, 2014.

29. Xie XJ, Li X, Wang F and Chen W: Cellular localization and tissue expression pattern of UCA1, a non-coding RNA. Nan Fang Yi Ke Da Xue Xue Bao 30: 57-60, 2010 (In Chinese).

30. Zheng Q, Wu F, Dai WY, Zheng DC, Zheng C, Ye H, Zhou B, Chen JJ and Chen P: Aberrant expression of UCA1 in gastric cancer and its clinical significance. Clin Transl Oncol 17: 640-646, 2015
31. Sun M, Xia R, Jin F, Xu T, Liu Z, De W and Liu X: Downregulated long noncoding RNA MEG3 is associated with poor prognosis and promotes cell proliferation in gastric cancer. Tumour Biol 35: 1065-1073, 2014.

32. Oh S, Kim N, Yoon H, Choi YJ, Lee JY, Park KJ, Kim HJ, Kang KK, Oh DH, Seo AY, et al: Risk factors of atrophic gastritis and intestinal metaplasia in first-degree relatives of gastric cancer patients compared with age-sex matched controls. J Cancer Prev 18: 149-160, 2013.

33. Yu J and Zhao Q: The demographic characteristics of histological types of gastric cancer with gender, age, and tumor location. J Gastrointest Cancer 40: 98-100, 2009. 